\title{
Building, Sustaining, and Supporting the Race, Ethnicity, and Politics Community
}

\section{INTRODUCTION: BUILDING, SUSTAINING, AND SUPPORTING THE RACE, ETHNICITY, AND POLITICS COMMUNITY}

\author{
Nadia E. Brown, Purdue University \\ Nazita Lajevardi, Michigan State University
}

DOI:10.1017/S1049096519001033

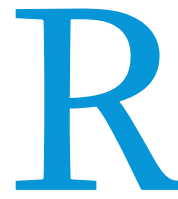

acial and ethnic minorities are grossly underrepresented in political science. APSA's most recent Diversity and Inclusion Report (2018) indicates that only $3.2 \%$ of members are Black Afro-Caribbean or African American, 6.9\% are East Asian or Asian American, $4.5 \%$ are Latino or Hispanic American, $0.2 \%$ are Native American, 1.1\% are Middle Eastern, $1.6 \%$ are South Asian or Indian American, and $3.2 \%$ are other. ${ }^{1}$ Moreover, these individuals are concentrated primarily in some fields and informally excluded from others. For instance, the same APSA report found that membership of scholars of color is overrepresented in the Race, Ethnicity, and Politics (REP) organized section: $22.2 \%$ are Black, Afro-Caribbean, or African American; 8.47\% are East Asian or Asian American; $\mathbf{1 3 . 7 \%}$ are Latino or Hispanic American; and only $38.14 \%$ are Non-Hispanic White or Euro-American. Comparatively, their membership in the Methodology organized section is staggeringly low: $80.72 \%$ of members are NonHispanic White but only $4.37 \%$ are Latino or Hispanic American, $4.88 \%$ are East Asian or Asian American, and 1.29\% are Black or African American. ${ }^{2}$

Given this underrepresentation in the discipline and overrepresentation in the REP section, we sought to systematically provide the perspectives of scholars who are actively challenging the norms of political science and advancing the goals of the section. Because this work often is seen as ancillary and not of general interest, REP scholars have created new outlets and used organic networks to promote their research while building community. These efforts often are supported by individual scholars without institutional and financial support. This spotlight highlights the varied ways that scholars have worked to develop communities that are largely unrewarded and ignored in mainstream political science. These efforts should be valorized and, as such, we spotlight the ways that others can support marginalized communities as a way to diversify the discipline. We are wholly committed to responding to the 2011 Pinderhughes APSA Presidential Task Force Report in which the contributors admonished the discipline for largely failing to give significant and meaningful attention to issues of race and ethnicity in political science. In doing so, we also highlight the intersectional ways that key actors within REP communities are committed to advancing scholarship by groups that often undertheorized within race- or ethnicity-only scholarship.

What are some of the ways that support for REP scholars and REP scholarship fostered? This spotlight highlights contributors whose service to the REP section subfield continues to build, sustain, and support community in myriad ways. The articles range substantially but together provide a glimpse into some of the methods that scholars are using to build the field. The spotlight covers a diverse array of topics, ranging from an editorial from one of the subfield's premier journals, showcasing how undergraduate research opportunities help to build the pipeline, highlighting the inclusiveness of the subfield's conferences and workshops, introducing the "People of Color Also Know Stuff" social media presence, discussing the importance of informal mentorship, and demonstrating immense and communal data-collection efforts. Importantly, it is inclusive of voices of scholars in all areas of the discipline, from graduate students to postdocs, to assistant, associate, and full professors. In summary, this collection of articles also provides best practices and suggestions for how the discipline and its subfields can follow the practices of the REP section to be more inclusive and diverse.

We know anecdotally that colleagues are making multiple efforts to build, sustain, and support the community, and these contributors are writing about the ways in which they have directed their efforts. Their efforts, of course, are targeted at community members in all stages-mentoring undergrads (formally and informally), graduate students, postdocs, assistant professors, and senior faculty-and we believe that these articles capture many of these strategies. Moving beyond anecdotal evidence, this spotlight uses the efforts of these key stakeholders in the REP field to advance our scholarly understanding of how and why diverse communities matter in political science.

\footnotetext{
NOTES

1. APSA Diversity and Inclusion Report (2018), Table 2. Available at www.apsanet org/Portals/54/diversity\%2oand\%2oinclusion\%2oprgms/DIV\%2oreports/ Diversity\%2oReport\%2oExecutive\%20-\%20Final\%2oDraft\%20-\%2oWeb\%2oversion. pdf?ver=2018-03-29-134427-467.

2. APSA Diversity and Inclusion Report (2018), Figure 4. Available at www.cambridge.org/core/membership/services/aop-file-manager/ file/5a7065fec871636539c5c70a/diversity-report-SPM.pdf.
}

\section{THE SUMMER RESEARCH OPPORTUNITIES PROGRAM AT MICHIGAN STATE UNIVERSITY}

Jamil S. Scott, Georgetown University

Kesicia A. Dickinson, Michigan State University

Eric Gonzalez Juenke, Michigan State University

Steven Thomas, Michigan State University

\section{DOI: $10.1017 / S_{1049096519001057}$}

The Summer Research Opportunities Program (SROP) is an intensive summer-research experience for undergraduate 